\title{
MRS Offers Short Courses Program at Spring Meeting
}

\author{
Vivienne Harwood Mattox, MRS Short Course Manager
}

During the 1986 MRS Spring Meeting a series of short courses are being presented for the first time on the West Coast. Courses are being held over a five-day period so that course attendees can take advantage of attending more than one course of interest to them. Some of the separate courses are designed so that together they present a comprehensive treatment of a diverse subject-an example is the series of courses on epitaxial growth. A limited number of scholarships are available to MRS student members who wish to attend one of the short courses. MRS Student Chapters are encouraged to make this opportunity known to their membership. Application forms may be obtained from MRS Headquarters
Special thanks are extended to the many MRS members who responded to the short course survey last Fall and volunteered their services to the MRS Short Course Program. Numerous individuals volunteered to distribute short course brochures and flyers within their organizations. This wide dissemination of knowledge about the program will contribute to its success. Offers for this type of assistance from other Society members are welcome. A major benefit of the survey was a list of suggestions for new course topics and course instructors.

Plans are under way to broaden the short course program to cover many new topics of interest to materials scientists and engineers. For the 1986 Fall Meeting several new courses are being developed in the area of materials characterization. Members are encouraged to identify areas of particular interest for which short courses should be offered. These suggestions should be directed either to Short Course Manager Vivienne Harwood Mattox (505) 294-9532, or to Education Committee Co-Chairman L. Ralph Dawson (505) 846-3451.

The MRS On-Site Short Course Program has had a successful start. Three courses have been offered with class sizes ranging from 30 to 50 attendees. Large organizations are benefiting from the enthusiasm generated from having an expert provide a tutorial on an important current topic of interest. On-site courses can be specifically tailored to the audience.

\section{ON-SITE SHORT COURSES} conducted at your own facilities or a nearby site

The best way to keep your staff on top of their fields is through an on-going program of continuing education. One of the most efficient, cost-effective methods is to bring experts to your geographical location so that they can teach the latest techniques, discuss the newest research, and talk to your staff about the actual problems that they face daily.

The economic savings of On-Site programs are considerable, both in terms of time and budget. There are no travel fees or hotel costs for your staff, and attendees lose minimal time from their work.

MRS On-Site courses will be adapted to the specific needs of the sponsoring organization and the management will have an opportunity to interact with the instructor to discuss the course emphasis. Written requests from organizations will be handled on a first-come, first-served basis. For further details of courses which are available, prices and other information, write or call:

\author{
Vivienne Harwood Mattox \\ MRS Short Course Manager \\ Materials Research Society \\ $\mathbf{4 4 0}$ Live Oak Loop \\ Albuquerque, NM 87122 \\ (505) 294-9532
}

